\title{
EPISTEMOLOGIA E AUTONOMIA DA GEOGRAFIA BRASILEIRA APLICADAS À ANÁLISE DAS DINÂMICAS DA PAISAGEM?1
}

\author{
Dirce Maria Antunes SUERTEGARAY²
}

\begin{abstract}
RESUMO
O texto constitui uma breve exposição, com o objetivo de responder à perguntatítulo. A centralidade analítica é a de tratar do conceito de paisagem, em articulação com as diversas possibilidades de caminhos interpretativos. Apresenta-se a articulação do conceito de paisagem com suas possibilidades de análise do espaço geográfico, no qual a paisagem constitui uma das possibilidades de particularizar a teia de relações que configura o espaço analisado pela Geografia. O texto está seccionado em três momentos. O primeiro discorre sobre a diferenciação de concepção e de uso analítico da paisagem. Na continuidade, de forma breve, são abordados exemplos de análise, a partir do conceito de paisagem, no Brasil. Ao final, busca-se uma possibilidade de resposta à pergunta proposta como título.
\end{abstract}

Palavras-chave: Paisagem. Epistemologia da Geografia. Conceitos geográficos.

\section{BRAZILIAN GEOGRAPHY'S EPISTEMOLOGY AND AUTONOMY APPLIED TO THE ANALYSIS OF LANDSCAPE DYNAMICS}

\begin{abstract}
The text is a brief exposition, in order to answer the title question. The analytical centrality is to deal with the concept of landscape, in articulation with the many possibilities of varied interpretative paths. The articulation of the landscape concept with its possibilities of analysis of geographic space is presented, in which the landscape is one of the possibilities of particularizing this web of relationships that configure the space analyzed by Geography. The text is sectioned in three moments. The first one discusses the differentiation of conception and analytical use of landscape. The following presents, briefly, examples of analysis that are approached from the concept of landscape in Brazil. In the last section, we try to find an answer for the question that is proposed in the title.
\end{abstract}

Keywords: Landscape. Epistemology of Geography. Geographical concepts.

\footnotetext{
${ }^{1}$ Texto apresentado em palestra realizada no II Congresso Brasileiro de Organização do Espaço e XIV Seminário do Programa de Pós-Graduação (II CBOE), realizado na cidade de Rio Claro/SP, entre os dias 24 a 28 de março de 2019, intitulado "Soberania e Ciência no século XXI: a decolonialidade do saber como novo paradigma geografia?".

2 Professora do PPGG - UFPB e POSGEA - UFRGS.
} 


\section{EPISTEMOLOGÍA Y AUTONOMÍA DE LA GEOGRAFÍA BRASILEÑA APLICADA AL ANÁLISIS DE LA DINÁMICA DEL PAISAJE}

\section{RESUMEN}

El texto es una breve exposición para responder a la pregunta del título. La centralidad analítica es abordar el concepto de paisaje, en articulación con las muchas posibilidades de diversos caminos interpretativos. Se presenta la articulación del concepto de paisaje con sus posibilidades de análisis del espacio geográfico, donde el paisaje es una de las posibilidades de particularizar esta red de relaciones que configuran el espacio analizado por la Geografía. El texto se secciona en tres momentos. El primero momento analiza la diferenciación de la concepción y el uso analítico del paisaje. A continuación, se abordan, brevemente, ejemplos de análisis del concepto de paisaje, en Brasil. Al final, buscamos la posibilidad de responder la pregunta propuesta como título.

Palabras clave: Paisaje. Epistemología de la Geografia. Conceptos geográficos.

\section{INTRODUÇÃO}

Este texto busca responder à pergunta-título. Esta foi, originalmente, proposta como uma afirmação, tendo sido, aqui, transformada em questão. Para tratar do tema, resgata-se o conceito de paisagem, em articulação com as possibilidades de análise, em Geografia.

O que se pretende apresentar é a articulação deste conceito com as possibilidades de análise do espaço geográfico, entendido como o uno múltiplo, no qual a paisagem constitui uma das possibilidades de particularizar a teia de relações que configura o espaço analisado pela Geografia.

Para isto, o texto apresenta três momentos: o primeiro diz respeito a um rápido resgate do surgimento e da diferenciação do conceito de paisagem. Esta diferenciação, é sabido, está presente, no contexto geográfico. Na continuidade, são trazidos exemplos de análise, a partir do conceito de paisagem, no Brasil e, ao final, busca-se uma possibilidade de resposta à pergunta proposta.

\section{SOBRE O CONCEITO DE PAISAGEM E SUA APLICABILIDADE}

De maneira ampla, identificam-se duas vertentes para o entendimento da paisagem: a italiana, renascentista, que trata da materialidade limitada, que, sob tal perspectiva, aponta para o que é exterior ao Homem, isto é, para aquilo que é visto, como recortado por uma janela, de um ponto de vista singular, 
expressando, portanto, um limite; e a alemã, influenciada pela sua cultura naturalista e estética (do Romantismo), que concebe a paisagem num contexto holístico, associado à conexão entre natureza, cultura e estética, a exemplo de Humboldt.

As disciplinas e/ou os campos científicos, desde o século XIX, quanto principiam a se consolidar, utilizam o conceito de paisagem sob diferentes enfoques. Alguns exemplos podem ser úteis, para ilustrar as diferentes formas de analisar a paisagem, nos diferentes campos disciplinares. A concepção de paisagem perpassa os clássicos da Geografia.

A paisagem, enquanto conceito, expressa o clássico princípio da análise geográfica da conexão. Este princípio está expresso na obra de Passarge (1926/1982), em texto escrito em 1926, em que propõe ampliar a compreensão do relevo, ajuntando à análise o conceito de paisagem.

Em seu texto, Passarge (1926/1982) escreve, referindo-se aos estudos geomorfológicos: "uma morfologia da paisagem terá que substituir a morfologia das zonas climáticas, porque é mais adequada a uma descrição e é uma explicação mais clara dos fenômenos" (PASSARGE, 1926/1982, p. 380, tradução nossa).

A Ecologia passa a utilizar o conceito de paisagem a partir dos anos de 1970. Suas referências partem da construção científica de Troll (1950), que concebe paisagem como a expressão da relação solo e uso, enfatizando a funcionalidade ecossistêmica, mas buscando o entendimento da forma e de sua distribuição, amparado na leitura da paisagem. Voltaremos a esse texto, mais adiante, para explicitar com maior detalhamento, a paisagem, nos estudos ecológicos.

Sob a visão humanista, ou aquelas que traduzem a compreensão das chamadas ciências sociais, temos, a partir da leitura de Huggett e Perkins (2004), que a História e a Arqueologia tratam da paisagem como marcas do passado; a Filosofia e Psicologia expressam suas análises, através da valoração do imaginário, dos mapas mentais, da imaterialidade; e a Arquitetura vincula a paisagem à materialidade e ao ordenamento das formas, no espaço, sobretudo, na cidade, em relação ao seu planejamento. 
A Geografia, por sua vez, tem o conceito de paisagem atrelado à concepção renascentista, na qual a paisagem é aquilo que a vista alcança e expressa a sua materialidade, e, portanto, é a expressão de um momento, ou à expressão da conjunção de diferentes dimensões e de seu movimento. Tal ideia enfatiza, na constituição das paisagens, o uso da terra e a sua expressão materializada, podendo ser compreendida, na sua forma (descrição), mas, também, na sua transformação ou, dito de outra forma, a análise da paisagem implica compreender a forma, em sua transformação (na sua dimensão histórica).

O aprofundamento disciplinar, na concepção e no uso desse conceito, promove a revisão das diferentes concepções, sobretudo entre concepções objetivas e subjetivas, e indica possibilidades múltiplas de análise da paisagem. Diz-se, então, que paisagem é um conceito polissêmico.

\section{PAISAGEM E FORMAS DE ANÁLISE}

Neste item, resgatamos alguns autores para expressar essa diferenciação analítica nos estudos de paisagem. Não é o objetivo, aqui, esgotar esta análise. São trazidos apenas alguns exemplos. Cabe lembrar que o conceito de paisagem está no âmago da Geografia e, se adentrarmos nas leituras dos clássicos, veremos que este foi um conceito-chave, para muitos deles. Parte da caracterização e das denominações relativas ao conceito de paisagem tomam como referência Huggett e Perkins (2004), acrescidas de concepções trazidas disciplinarmente, por outros autores. Inicia-se, esta caracterização, a partir da Ecologia.

\section{ECOLOGIA}

A paisagem, conforme Huggett e Perkins (2004), na perspectiva ecológica, se constitui de arranjos de unidades de uso da terra. Analiticamente, os ecólogos buscam padrões, considerando como critério a homogeneidade interna de uma paisagem, em relação à heterogeneidade externa. Sob esta perspectiva, consideram como elementos: formas de uso, tipo de solo, cobertura vegetal, uso da terra, entre outros. O objetivo da análise está centrado na identificação de padrões (áreas homogêneas), de corredores (espaços de 
transição e de conexão), da Matrix (matriz), ou seja, do ecossistema de contexto. Em termos analíticos, esta concepção busca revelar a funcionalidade pela diferenciação, entre áreas homogêneas e heterogêneas. Por exemplo, a cobertura da terra original $\mathrm{x}$ uso, em um determinado espaço, pode formar um mosaico heterogêneo. Este, por sua vez, revela transformações, na funcionalidade, na medida em que a heterogeneidade rompe com a matriz original, detentora do que seriam a funcionalidade e as formas originais.

\section{GEOMORFOLOGIA}

$\mathrm{Na}$ análise geomorfológica, a paisagem é concebida como um conjunto homogêneo de formas, definidas através de métricas, que, combinadas, formam redes ou mosaicos, podendo ser, ainda, compreendida como um conjunto de formas, produto de uma funcionalidade (dinâmica) temporal-espacial, ou seja, do entendimento de processos do presente e do passado. Assim compreendida, revela uma estrutura constituída da identidade de elementos e da funcionalidade (conexão) comum, para um conjunto de feições. Apresenta homogeneidade.

A paisagem, em Tricart (1979), entretanto, é entendida "como uma tradução concreta e espacial de um ecossistema. No funcionamento da paisagem e do ecossistema, suas evoluções se confundem" (TRICART, 1979, p. 473), admitindo que, sob esta perspectiva, poderiam ser introduzidas as intervenções humanas.

Tricart (1979), ao fazer esta conexão, indica duas dimensões: de um lado, a espacialidade definida pela paisagem e, de outro, a funcionalidade da dimensão ecológica.

\section{GEOGRAFIA CULTURAL}

Tomemos outro exemplo: o conceito de paisagem construído por Sauer (1931/1982), através de uma leitura livre. Interpreta-se que paisagem, para esse autor, é um complexo de influências, resultantes de fatores naturais e culturais em interação, derivando em feições materiais, associadas a processos históricos de constituição. 
Decorre de Sauer (1931/1982), no contexto da Geografia cultural empirista, uma concepção de paisagem expressa pela forma. Neste sentido, há uma similaridade com os estudos ecológicos, os quais enfatizam a forma e a funcionalidade, aqui, associadas à dimensão cultural e, na ecologia, associadas aos usos dos recursos. Nesta perspectiva, a paisagem é forma e é fruto da diversidade cultural, ou seja, é produto dos diferentes modos de viver.

Nesse mesmo contexto, tem-se, na atualidade, a paisagem como meta narrativa, na denominação de Huggett e Perkins (2004), que se constitui em uma perspectiva analítica que privilegia a existência, a arte, o texto, a poesia, a música, pois utiliza-se de metáforas, na compreensão da paisagem. Neste caso, os pesquisadores enfatizam a memória individual ou coletiva. Estas são construídas de forma livre e, para além das metáforas, as análises refletem diferentes processos sociais, incluindo poder e arte (estética), no contexto de construção de identidades.

Panitz (2012) estuda a paisagem e suas representações, a partir dessa perspectiva. Dessa forma, aborda, em seu texto, os usos deste conceito, sob diferentes perspectivas: literatura, artes visuais e música. Ao longo de seu texto, discorre minuciosamente sobre o tema, demonstrando a diversidade de análises, construídas a partir da Geografia Cultural.

\section{GEOGRAFIA, ARQUEOLOGIA E ARQUITETURA}

Para expressar uma possibilidade de aproximação entre campos do conhecimento, trazemos aqui os elementos de aproximação da paisagem, na Geografia, na Arqueologia e na Arquitetura. Essa aproximação está associada à compreensão da "paisagem como palimpsesto", na denominação de Huggett e Perkins (2004).

Segundo esses autores, o ponto comum entre estas áreas do conhecimento diz respeito à análise dos processos do passado, que subsistem, na paisagem contemporânea ou vice-versa. $\mathrm{Na}$ maioria das vezes, a materialidade produzida por esta paisagem é explicada pelo uso e pelo valor, conforme se configuram, ao longo de um tempo. Há diferenças analíticas, no entanto, na Geografia cultural (em algumas abordagens): aquelas de enfoque 
empírico aparecem divorciadas de argumentos críticos sobre os processos sociais e da dialética entre uso e valor.

Há enfoques associados à forma, à função e aos processos, considerando o valor paisagístico de uso ou de troca: são as paisagens estudadas como patrimoniais ou turísticas.

Da mesma forma, esta paisagem vem sendo lida como registro e como resgate da cultura passada, como espaços de abrigo e de resistência ou, ainda, nesse contexto, de um ponto de vista subjetivo, como aquela que valoriza e que resgata identidades e a memória subjetiva.

\section{PAISAGEM NA GEOGRAFIA BRASILEIRA}

Neste item, não é a intenção esgotar a análise, que seria uma tarefa imensa. Trazemos, apenas, três exemplos, de períodos díspares e sob diferentes abordagens, a título de reflexão.

Iniciamos, exemplificando estudo da paisagem, a partir da Geomorfologia e de sua proposta analítica, conforme Ab'Saber (1969). Seus estudos geomorfológicos o levam a propor uma metodologia de análise, a partir do conceito de paisagem. Esta está ancorada em três conceitos: a compartimentação, a estrutura superficial e a fisiologia da paisagem.

A Compartimentação se define pela identificação de unidades, através da diferenciação geométrica das formas de relevo. A Estrutura implica compreender a gênese/formação da paisagem, através do resgate de indicadores históricos. Em geomorfologia, os estudos da estrutura tratam de resgatar as evidências de formas ou de depósitos correlatos aos ambientes do passado. A Fisiologia implica compreender a funcionalidade, a ação dos processos modeladores das formas, sobretudo, no presente. Interessa o estudo da dinâmica, da funcionalidade da paisagem, sua dinamicidade atual, incluindo a ação antropogênica.

Tomemos, no campo da geografia humana, o exemplo de Milton Santos (1996). Para ele, a paisagem é entendida como um sistema de objetos. É a materialidade, a partir de um ponto de vista. Registra, em suas formas heranças, o que denominou de rugosidades. São, portanto, transversais: a materialidade 
do passado persiste, no presente, podendo mudar sua função. Ou seja, perpassa e registra vários tempos.

Um terceiro exemplo é a proposição de Verdum (2012). Este autor, sob uma perspectiva ampliada, indica três possibilidades, que, para ele, não são necessariamente excludentes. Trata-se do que denomina paisagem descritiva: o estudo das formas, através de seus elementos; paisagem sistêmica, que consiste na análise funcional ou na combinação dos elementos físicos, biológicos e sociais, indissociáveis; e paisagem perceptiva (BERQUE, 1995), constituída de Marca e de Matriz, em que Marca incidiria na análise da forma e Matriz, na percepção, na concepção e na ação. Neste caso, a paisagem é materialidade e imaterialidade, tratando-se de decifrar o real e o imaginário, enquanto presente e/ou enquanto projeção do futuro.

A polissemia deste conceito permite que, na diversidade de possibilidades analíticas, possamos inferir que paisagem é compreendida como forma, o que, nesse sentido, implica considerar sua materialidade, sua localização, sua distribuição, sua constituição de homogeneidade/heterogeneidade e sua diversidade.

Em relação a sua função, são-lhe atribuídas características, como de serviço, de valor de uso, de valor de troca, de estética, de ética e de patrimônio. Por sua vez, o resgate da funcionalidade implica reconhecer sua dinâmica e os processos que a transformam e/ou a produzem.

Ainda, pode-se conferir à paisagem implicações de tempo/espaço, avaliando suas temporalidades espaciais. Da mesma forma, é expressão de representações de identidade, de memória.

Estas manifestações analíticas promovem, por vezes, divergências; entretanto, é possível pensar que paisagem constitui um conjunto de elementos materiais e imateriais, em interação, no espaço-tempo.

\section{AUTONOMIA DA GEOGRAFIA BRASILEIRA, NA ANÁlISE DA DINÂMICA DA PAISAGEM?}

A pergunta que se coloca, como tema deste texto: existe autonomia da Geografia brasileira, em relação à dinâmica da paisagem?É uma pergunta complexa. Pressupõe, esta questão, um entendimento do conceito/significado 
de paisagem que corresponda a uma construção geográfica autônoma. Do que se conhece, na atualidade, o conceito de paisagem é equivalente e discutido, com base em autores estrangeiros, das mais diferentes matrizes. Isto significa dizer que, na Geografia brasileira, esse conceito é tão polissêmico quanto o é, de resto, nos diferentes centros de pesquisa, ao longo do mundo.

Conceitos fazem parte de uma rede que dá sustentação a uma explicação teórica, e a história do conceito de paisagem, seja na arte ou na ciência, no Brasil, tem a ver com a Geografia que herdamos, seja dos clássicos, seja de autores contemporâneos.

Desloco, então, a pergunta, para, talvez, o que foi desejado perguntar: qual é o construto geográfico que, no nosso contexto histórico, foi estabelecido, considerando o conceito de paisagem?

De maneira ampla, podemos dizer que nossas paisagens, seja em escala nacional ou regional, foram estabelecidas pelo olhar eurocêntrico, para o bem ou para o mal. Desde o Brasil Colônia, a paisagem brasileira é descrita e é representada pela sua possibilidade de uso (diversidade) e pelos seus riscos tropicais, pela adversidade de clima e pela possibilidade de doenças.

A partir dos relatos, das imagens e dos estudos sobre o Brasil, seja pelas artes gráficas, pela literatura ou pela produção científica, ao longo de nossa história, construíram-se representações da paisagem brasileira, indicando: a adversidade do clima, a abundância de recursos, o vazio amazônico, o semiárido hostil e seu discurso da seca, a europeização do Sul e a ideia de um outro país, entre outros tantos exemplos.

Tomando como referência a autora argentina Silvestri (2011), percebe-se que esta indaga sobre o tema aqui exposto, em El destino de la patria. A autora resgata a noção de sublime, que se produz, na primeira metade do séc. XX, naquele país, referindo-se às representações construídas sobre o Pampa argentino, cujo reconhecimento é feito, a partir do conceito de paisagem, na sua grandeza e na sua dimensão natural. Para a autora, trata-se de um sublime centrado na ideia de extensão e de serenidade, que, por sua vez, articula-se com as representações relativas à nação argentina. 
O que se deseja trazer ao debate é: o conceito de paisagem, presente na Geografia, por ser polissêmico, não expressa um único caminho analítico. Ficam, portanto, as perguntas: que nível de autonomia se deseja? Qual é a possibilidade dessa construção autônoma? Tal construção poderia ser embasada na diversidade das sociedades da América Latina? Seria possível, nesse contexto, a organização de um entendimento que situe a paisagem fora das concepções aqui expressas? O que, para nós, significa paisagem? É possível um consenso?

E mais: neste caso, restaria um caminho, na decifração ou no entendimento do conceito de paisagem, na convivência e na luta pela transformação do mundo contemporâneo, a partir dos movimentos sociais, dos grupos e das sociedades que compõem a América Latina, nas suas diferentes cosmovisões? Qual seria o potencial de diversidade destes conceitos, no embate político, considerando a análise da dinâmica da paisagem centrada nesse olhar diverso? Enfim, poderíamos construir análises e representações de engajamento e de resistência e, quem sabe, construir uma Geografia da análise da paisagem mais autônoma?

O exemplo trazido de Escobar (2009) é revelador, quanto à preocupação para com o entendimento de paisagem, na perspectiva de autonomia. A análise de seu texto permite dizer que o embate que questiona a destruição de seus espaços de vida está centrado na defesa de sua localização, ou seja, é feito a partir dos sujeitos ou das populações originárias do continente americano, que vivem sob determinadas paisagens. A resistência e a luta destes povos se fazem, através de um compromisso... com a vida.

Aqui, há uma referência à paisagem. Esta pode nos levar a deduzir que, na busca de autonomia, pelos povos, a resistência se faz pela e com a paisagem, entendida, esta, não necessariamente, como algo externo e passível de observação; ao contrário, a paisagem aqui expressa se insere, na vida destas populações, abrangendo os seres vivos e os não vivos e resguardando as suas manifestações diversas.

[...] la gente se moviliza en contra de los aspectos destructivos de la globalización desde la perspectiva de lo que ellos han sido y de lo que son en el presente: sujetos históricos de culturas, economías y ecologías particulares; productores particulares de 
conocimiento; compromiso de individuos y colectividades con el juego de vivir con los paisajes, con los seres vivos y no vivos, $\mathrm{y}$ de manera particular entre sí. (ESCOBAR, 2009, p. 66)

É revelador, neste breve texto, o fato de que a resistência se faz pela defesa da cultura, da economia e das ecologias particulares, associadas ao jogo do viver com as paisagens, enquanto produto histórico indissociável de suas práticas e do conhecimento construído, neste processo.

Essa leitura poderá encaminhar à reflexão sobre um conceito de paisagem que permita uma análise, não, somente, descritiva, da forma e da expressão, exclusiva da materialidade, que ainda predomina, em muitas das análises geográficas.

\section{FINALIZANDO}

O que se pode encaminhar, diante desta breve apresentação de alguns conceitos de paisagem, é que: conforme referimos, paisagem, enquanto conceito, na Geografia brasileira, por mais polissêmico que seja, expressa, na sua construção, diferentes caminhos analíticos, ora se aproximando do campo científico, ora do campo das artes.

A relação da paisagem com a ciência e com a arte advém da Modernidade, mas, ainda que perpassada por novas leituras, está presente, neste período atual, nas perspectivas ampliadas e resgatadas de autores contemporâneos de expressão internacional.

Os aportes deste conceito não expressam uma autonomia ou um construto, no âmbito da Geografia brasileira, de forma autônoma. Considerando a pergunta inicial, proposta para debate, neste evento, ficam as perguntas: que nível de autonomia se deseja? Qual a possibilidade dessa construção autônoma? Tal poderia ser embasada na construção da diversidade das sociedades da América Latina? Seria possível, nesse contexto, a construção de um entendimento que situe a paisagem fora das concepções aqui expressas? O que, para nós, significa paisagem?

Retomando o texto de Arturo Escobar (2009), do fragmento que se refere ao pressuposto das lutas dos povos originários, enquanto: "compromiso de individuos y colectividades con el juego de vivir con los paisajes, con los 
seres vivos y no vivos, y de manera particular entre sí." (ESCOBAR, 2009, p. 66, grifo do autor), podemos extrair um sentido, que se explicita, em sua escrita, numa concepção de paisagem associada à natureza e a seus recursos, incluindo os seres vivos. Tal posição implica, também, entender que a luta dos povos originários expressa uma necessidade de defender a paisagem, enquanto sua condição de existência, de manutenção de vida e de cultura.

Daí, podemos inferir que Escobar, ao se referir, no texto, à paisagem, revela uma compreensão que nos remete a conexões, não cabendo uma análise seccionada dos diferentes constituintes da paisagem. Por outro lado, paisagem é materialidade, sendo, também, imaterialidade.

As representações, que fazem do lugar que habitam uma paisagem, revelam a totalidade de seu espaço de vivência e a imbricada relação naturezasociedade-cultura, vinculada ao sentido de suas existências.

Não é por outra razão que sabemos, hoje, que os povos originários não só mantiveram sua paisagem, como criaram paisagens, na mesma medida que coexistiram com elas, sem, contudo, desconstruí-las ou transfigurá-las.

Certamente, essa compreensão contribui para um outro entendimento do conceito de paisagem. Se atentarmos ao fato de que, de forma mais abstrata, paisagem pode ser concebida como uma conjugação de elementos (materiais e imateriais), no espaço-tempo, sua polissemia, reveladora de e por muitos métodos, pode ser reavaliada, enquanto processo de fragmentação.

\section{REFERÊNCIAS}

AB'SABER, A. N. Um conceito de geomorfologia a serviço das pesquisas sobre o Quaternário. Geomorfologia, São Paulo, n. 18, p. 1-23, 1969.

BERQUE, A. Le paysage de la modernité. In: BERQUE, A. Les raisons du paysage, de la Chine antique eux environnements de de synthèse. Paris: Editions Hazen, 1995, p. 103-140.

ESCOBAR, A. Ecología política de la globalidad y la diferencia. In: ALIMONDA, Héctor. La naturaleza colonizada: economia política e mineria en America Latina, Ediciones CICCUS, CLACSO, 2009, p. 77. (Colección Grupos de Trabajo) 
HUGGETT, R.; PERKINS, C. Landscape as form, process and meaning. In: MATTHEWS, J. A.; HERBERT, D.H. (ed.). Unifying geography: Common heritage, shared future. London: Routledge, 2004.

PANITZ, L. M. O estudo das paisagens e suas representações a partir de produtos culturais. In: VERDUM, R.; SANTOS VIEIRA, L. de F.; PINTO, B. F.; DA SILVA, L. A. P. Paisagem. Leituras. Significados. Transformações. Porto Alegre: Editora da UFRGS, 2012.

PASSARGE (1926/1982). Morfologia de zonas climáticas o geomorfologia de paisages? In: MENDOZA, J. G.; JIMÍNEZ, J. M.; CANTERO, N. O. El pensamiento geográfico. Madrid: Alianza Editorial, 1982.

SANTOS, M. A natureza do espaço - Técnica e tempo. Razão e emoção. São Paulo: Hucitec, 1996.

SAUER. C. La geografia Cultural. In: MENDOZA, J. G.; JIMÍNEZ, J. M.; CANTERO, N. O. El pensamiento geográfico. Madrid: Alianza Editorial, 1982.

SILVESTRI, G. El lugar común. Una historia de las figuras de paisaje en el Río de la Plata. Buenos Aires: Edhasa, 409 p., 2011. ISBN 978-987-628$117-1$

TRICART, J. El analisis de sistemas y el estúdio integrado del médio natural. In: MENDOZA, J. G.; JIMÍNEZ, J. M.; CANTERO, N. O. El pensamiento geográfico. Madrid: Alianza Editorial, 1982.

TROLL C. El paisage Geográfico y su investigación. In: MENDOZA, J. G.; JIMÍNEZ, J. M.; CANTERO, N. O. El pensamiento geográfico. Madrid: Alianza Editorial, 1982.

VERDUM, R. Perceber e Conceber a paisagem. In: VERDUM, R.; SANTOS VIEIRA, L. de F.; PINTO, B. F.; DA SILVA, L. A. P. Paisagem. Leituras. Significados. Transformações. Porto Alegre: Editora da UFRGS, 2012. 